\title{
CAPITAL INTELECTUAL: EVIDÊNCIAS DE SEUS ELEMENTOS EM UMA COOPERATIVA AGROPECUÁRIA
}

RESUMO: Dada a importância do Capital Intelectual para o sucesso organizacional e do escasso número de estudos que abordam essa temática no contexto do agronegócio, este estudo teve por objetivo verificar a presença dos elementos formadores do capital intelectual em uma cooperativa agropecuária visando contribuir para o preenchimento dessa lacuna na produção científica nacional. Como principal contribuição, este estudo apresenta evidências de forte presença de todos os elementos formadores do Capital Intelectual, sendo eles o Capital Humano $(4,062)$, Capital Relacional $(4,063)$ e o Capital Estrutural $(4,000)$. Quanto à importância da identificação do Capital Intelectual por parte do gestor, verificou-se que o Capital Intelectual é importante e a sua evidenciação é relevante para a tomada de decisão.

Palavras-chave: Capital Humano. Capital Relacional. Capital Estrutural.

\section{INTELLECTUAL CAPITAL: EVIDENCE OF ITS ELEMENTS IN AN AGRICULTURAL COOPERATIVE}

ABSTRACT: Given the importance of Intellectual Capital for organizational success and the scarce number of studies that address this issue in the context of agribusiness, this study aimed to verify the presence of the elements that form the intellectual capital in an agricultural cooperative aimed at contributing to fill this gap in national scientific production. As a main contribution, this study presents evidence of a strong presence of all the elements that form Intellectual Capital, being Human

\footnotetext{
${ }^{1}$ Graduanda em Ciências Econômicas (UFGD). Universidade Federal da Grande Dourados. Mato Grosso do Sul. Brasil. E-mail: leticiadorce@hotmail.com

${ }^{2}$ Mestrando em Agronegócios (UFGD), Especialista em Gestão de Pessoas (UCDB), Graduado em Ciências Contábeis (UFGD). Atualmente é Professor dos Cursos de Administração e Ciências Contábeis da Faculdade de Educação, Tecnologia e Administração de Caarapó - FETAC. Mato Grosso do Sul. Brasil. E-mail: rafaeltodescato@hotmail.com

${ }^{3}$ Pós-doutor em Finanças (FEA/USP), Doutor em Administração (Universidad de León e Universidade Federal de Viçosa), Doutor em Engenharia de Produção e Sistemas (UFSC), Mestre em Administração de Empresas (PUC/SP). Atualmente é professor da Faculdade de Administração, Ciências Contábeis e Economia da Universidade Federal da Grande Dourados. Mato Grosso do Sul. Brasil. E-mail: regiogimenes@ufgd.edu.br
} 
Capital (4,062), Relational Capital $(4,063)$ and Structural Capital $(4,000)$. Regarding the importance of the identification of Intellectual Capital by the manager, it was verified that Intellectual Capital is important and its evidence is relevant for decision making.

Keywords: Human capital. Relational capital. Structural capital.

\section{INTRODUÇÃO}

Com a evolução do mundo pós-moderno, a era industrial foi substituída pela era da informação, transformando o conhecimento em uma importante ferramenta que passou a ter grande valor, em um contexto de economias globalizadas e um ambiente empresarial competitivo e inovador. O fato é que o conhecimento "tornouse um recurso econômico proeminente, mais importante que a matéria-prima e por muitas vezes mais que o dinheiro" (STEWART, 1998, p. 5).

Dessa maneira os recursos existentes até então, valorizados e utilizados na produção: terra, capital e trabalho, aliaram-se ao conhecimento, permitindo assim transformar a estrutura econômica das nações e, principalmente, valorizar o ser humano (ANTUNES; MARTINS, 2007a).

Em organizações empresariais a aplicação do conhecimento como um recurso produtivo, juntamente com as tecnologias disponíveis condicionam benefícios intangíveis que permitem agregar valor às organizações. Portanto, o conhecimento organizacional ou capital intelectual como pode ser definido, é o conhecimento adquirido e aplicável, tornando-se um ativo intangível com elevada capacidade de originar benefícios econômicos para as organizações que fazem sua gestão (BROOKING, 1997).

De acordo com Brooking (1996), o capital intelectual não é um conceito novo, porque se originou a partir das relações, ou seja, do momento em que o primeiro vendedor estabeleceu uma boa relação com um cliente. A abordagem do termo capital intelectual não é recente, sendo discutido pela primeira vez ao longo década de 60 , quando se analisava a contribuição do conhecimento dentre os demais fatores de produção.

Dessa maneira, surgiram diversos conceitos de capital intelectual, dentre os quais se destaca o de Edvinsson e Malone (1998), muito utilizado na literatura que 
aborda este assunto. Para estes autores, o conhecimento pode ser convertido em valor (lucro) para as organizações. Já Stewart (1998) considera que o capital intelectual é a soma do conhecimento de diferentes componentes em uma organização, permitindo a mesma uma vantagem competitiva.

Segundo Antunes e Martins (2007b) o capital intelectual tem relação direta com os elementos intangíveis, ou seja, é a soma do conhecimento e das habilidades proveniente dos integrantes da organização com a finalidade de agregar vantagem competitiva, sustentada em bons relacionamentos e no desenvolvimento de inovações tecnológicas.

As organizações de qualquer espécie têm se preocupado em utilizar o conhecimento como um instrumento gerencial, dessa forma o constante uso da informação tem tornado as organizações dependentes do conhecimento como fonte de lucro, pois atrai os consumidores e clientes (STEWART, 1998). De acordo com Oliva (2014), a Gestão do Conhecimento é utilizada por organizações que buscam eficácia e eficiência nos seus procedimentos administrativos, logo esta técnica às vezes não é formalizada. Contudo formalizar ajuda a disseminar o conhecimento promovendo níveis mais elevados de eficiência dentro das organizações. Portanto a divulgação da Gestão do Conhecimento detecta as possíveis melhorias a serem implantadas nas organizações, e permite também, identificar o feedback dos investimentos feitos em conhecimento (CHUA; GOH, 2008).

Diversos estudos sobre o capital intelectual foram realizados no Brasil abrangendo as dificuldades encontradas no processo de gestão e evidenciação (REIS, 2005), a importância e percepção dos gestores quanto a sua mensuração (ANTUNES, 2005; BARBOSA; GOMES, 2002; CARLOS FILHO et al., 2014), a evidenciação e o disclosure (CRUZ; ALVES, 2013; ARRUDA, 2009; REINA et al., 2011; SOUSA, et al. 2008; BARROS; PONTE; FARIAS, 2007), modelos de mensuração (JOIA, 2001; JOIA, 2009; ENSSLIN; et al. 2008; VARGAS; et al. 2008) e a elaboração de relatórios de divulgação (ANTUNES, 2006; OLIVEIRA; BEUREN, 2003).

A identificação de elementos do capital intelectual também tem sido agenda de pesquisa no contexto científico nacional, como observa-se nos estudos de Colauto et al. (2011), Silva, Nagano e Merlo (2008), Santos, et al. (2016), entretanto poucos estudos tratam da identificação de elementos formadores do capital 
intelectual, especialmente em organizações que atuam no setor do agronegócio. O estudo sobre a produção científica nacional realizado por Dorce, Cavalheiro e Gimenes (2017) demostrou que o único estudo cujo objeto situava-se no setor do agronegócio foi o de Nagano, Matheus e Merlo (2005) no contexto de usinas sucroalcooleiras, não identificando nenhum estudo que aborde as cooperativas.

As cooperativas podem ser um impulsionador de setores econômicos (SOARES; SOBRINHO, 2008) e representam um importante mecanismo de promoção do desenvolvimento local sustentável, principalmente de regiões onde predominam as atividades agropecuárias.

Nesse sentido, por existirem poucos estudos sobre os elementos formadores do capital intelectual no contexto das cooperativas, surge a questão que norteia este estudo: os elementos formadores do capital intelectual estão presentes no contexto das cooperativas agropecuárias? Sendo então o objetivo do presente estudo, verificar a presença dos elementos formadores do capital intelectual em uma cooperativa agropecuária visando contribuir para a difusão ainda embrionária desta temática no ambiente das cooperativas e do agronegócio.

O trabalho estrutura-se o em cinco seções. Esta primeira seção aborda a introdução da temática, a segunda apresenta a revisão da literatura, em seguida, a terceira, tratada metodologia utilizada no estudo, na quarta são apresentados os resultados e discussões da pesquisa, na quinta e última seção, as considerações finais.

\section{REFERENCIAL TEÓRICO}

\subsection{COOPERATIVAS AGROPECUÁRIAS ENQUANTO ORGANIZAÇÕES}

O cooperativismo teve sua origem na Inglaterra em 1844 no bairro de Rochdale, em Manchester, na Inglaterra, onde surgiu a primeira cooperativa moderna chamada de "Sociedade dos Probos de Rochdale" que se estabeleceu pautada em valores e princípios morais dentre os quais, destacavam-se a honestidade, a solidariedade, a equidade e a transparência, fundamentos que são considerados até a atualidade, como os pilares do cooperativismo (OCB, 2017). 
Um dos principais ramos do cooperativismo é o cooperativismo agrícola ou agropecuário que teve inicio no Brasil a partir de 1906, pela união de produtores rurais, em sua maioria, imigrantes europeus (origem alemã e italiana). Os imigrantes trouxeram consigo a bagagem cultural de seus países de origem, como, por exemplo: o trabalho associativo, a experiência de atividades familiares comunitárias, incentivando assim a criação de novas cooperativas no Brasil (OCB, 2017).

De maneira geral, as cooperativas agropecuárias são compostas por produtores rurais incluindo também agropastoris e pesca que desempenham as atividades de forma solidária e participativa no desenvolvimento de todas as etapas do processo produtivo, ou seja, desde a compra de insumos para a produção, armazenagem, industrialização e comercialização dos produtos junto aos mercados consumidores SEBRAE (2009). Portanto as cooperativas têm a finalidade de promover a compra em comum de insumos para a produção agropecuária, propiciando benefícios (vantagens econômicas) que de certa forma não seriam disponibilizados aos produtores rurais atuando individualmente.

No que diz respeito ao processo administrativo, a gestão dos negócios nas cooperativas agropecuárias, especialmente nas últimas décadas, sofreram algumas transformações substanciais. Dentre elas há necessidade das cooperativas se estabelecerem em um novo contexto, globalizado e competitivo, mantendo a continuidade de suas atividades na busca da promoção do bem estar econômico e social dos seus associados. Desta forma estas organizações precisam desenvolver estratégias inovadoras que permitam maximizar as oportunidades e minimizar os efeitos das possíveis ameaças deste novo contexto (COELHO; FERREIRA, 2010). Estas estratégias agrupam-se genericamente em duas escolhas: liderança em custos ou diferenciação dos produtos ou serviços (PORTER, 1991).

Os talentos individuais e hábitos de liderança dos colaboradores de uma organização permitem que a mesma cumpra sua missão com eficiência e eficácia, em razão dos líderes corporizarem o conhecimento, convertendo-o em vantagens competitivas (ANTUNES, 2000). Desse modo o bom desempenho das empresas associadas ao setor agropecuário não é um elemento visível ou obtido somente com investimentos financeiros. Desta maneira os ramos do Agronegócio precisaram continuamente do capital humano e de suas habilidades para a efetivação de negócios internos e externos aos países, criando assim a necessidade de tornarem- 
se competitivos e inovadores, e estas características estão fortemente vinculadas com investimentos em conhecimento (SHELMAN; CONOLLY, 2012).

As cooperativas apresentam algumas peculiaridades no que se refere ao modelo de gestão se comparadas ao modelo adotado nas sociedades de capital. Esta complexidade não resulta somente do gerenciamento e análise de variáveis pertinentes ao próprio processo, mas também de características e problemas particulares das cooperativas (ZYLBERSZTAJN, 2002). As cooperativas não dispõem da mesma eficiência que as sociedades de capital devido, principalmente, a seus cooperados terem uma limitação de seus direitos de propriedade sobre a sociedade, além dos altos custos de agência (COOK; ILIOPOULOS, 1998). Portanto há muitos problemas associados com a distinção entre propriedade e controle os quais se tornam mais complexos nas cooperativas (COELHO; FERREIRA, 2010).

Ainda há problemas de eficiência nas cooperativas. O problema do carona é resultante do comportamento oportunista do cooperado em beneficiar-se de bens e direitos coletivos, portanto refere-se a cooperados que não realizam investimentos e desfruta das mesmas vantagens que os cooperados que efetivaram investimentos (FERREIRA, 2005). Já o problema de horizonte refere-se à limitação temporal do planejamento da cooperativa, ou seja, é relativo aos direitos de propriedade, não sendo transferidos quando os membros saem da sociedade (COELHO; FERREIRA, 2010).

Já o problema de controle, melhor explicado por Zylbersztajn (2002), refere-se à qualidade de gestão do agente, pois quando a administração é desempenhada por um agente que não possui a capacidade suficiente, geram-se problemas de eficiência, que são verificados rapidamente pelo mercado, especificamente em sociedades de capital aberto, seja devido à queda do valor das ações, como também a posição de risco do empreendimento.

O maior desafio das cooperativas é a estrutura extremamente sensível para acompanhar as exigências do mercado de qualificação, inovação (diversificação) e flexibilidade. A causa desta fragilidade resulta das dificuldades de ordem estrutural e falta de percepção administrativa que limita a ascensão de novos mercados (MELLO; RICCI, 1996). Portanto, os principais pontos fracos do segmento cooperativo podem ser apontados como falta de capacitação gerencial, procedimentos inadequados de qualificação, incapacidade dos gestores ao 
adquirirem funções, fragilidade dos processos de controle do sistema (DENACOOP, 1996).

\subsection{CAPITAL INTELECTUAL}

A partir da década 90, as abordagens sobre o capital intelectual nas organizações começaram a se intensificar. Brooking (1996), Edvinsson e Malone (1998), Stewart (1998) e Sveiby (1998) foram os pioneiros nas discussões sobre o capital intelectual. Tais autores sistematizaram e classificaram o capital intelectual, buscando também os procedimentos metodológicos para sua evidenciação e mensuração.

A classificação do capital intelectual, conforme Brooking (1996) está subdividida em quatro pontos centrais: 1) ativos de mercado, representados pelo potencial da empresa em razão dos intangíveis constituídos pelas marcas, carteira de clientes, fidelidade dos clientes, negociação e canais de distribuição; 2) ativo humano, definido pelo benefício criado por parte dos indivíduos, por meio do conhecimento, expertise, criatividade, capacidade para resolver problemas, tudo de maneira grupal e dinâmica; 3) ativos de propriedade intelectual, know-how, segredos industriais, copyrigth, patentes e design, que correspondem aos ativos que demandam proteção legal (patentes), permitindo assim benefícios às organizações e 4) ativos de infraestrutura, corporificados pela estrutura produtiva organizacional como um todo, tais como, tecnologias, metodologias e processos empregados, sistemas de informações, modelos gerenciais, aceitação ao risco e banco de dados de clientes.

Já a classificação do capital intelectual a partir da sistematização de Edvinsson e Malone (1998) está centrada em dois pontos determinantes: 1) capital humano, como sendo a somatória de conhecimento, habilidades, capacidade, criação e competência dos empregados em desenvolver atividades, elementos formadores da cultura organizacional; e 2) capital estrutural, ligado à estrutura organizacional, como por exemplo, hardware, software, banco de dados, patentes, marca, ou seja, é todo o sistema que sustenta a produtividade dos empregados e também dos clientes. 
Edvinsson e Malone (1998, p. 40), definem o capital intelectual como "a posse de conhecimento, experiência aplicada, tecnologia organizacional, relacionamentos com clientes e habilidades profissionais que proporcionam à empresa uma vantagem competitiva no mercado". A definição de capital intelectual, que se tornou característica destes autores, foi baseada na metáfora da árvore, na qual sua parte visível (troco, galhos e folhas) são bens representados/evidenciados, por meio das demonstrações contábeis, e por sua vez, as raízes, a parte oculta da árvore, define o capital intelectual e sustenta a organização visível, sugerindo, portanto, que o capital intelectual é a base de crescimento e sustentabilidade das organizações.

Sveiby (1998) criou um dos modelos de avaliação para o ativo intangível, denominado "monitor de ativos intangíveis", especificamente a do capital intelectual, permitindo sua mensuração e classificação em três grupos centrais: 1) estrutura externa: estabelecendo relação direta com a marca, com os clientes, fornecedores e a imagem da empresa; 2) estrutura interna: representada pela estrutura organizacional, desde os sistemas de gerenciamento até os investimentos em pesquisa e desenvolvimento; 3) competência individual: que corresponde a habilidade e capacidade dos empregados em realizar tarefas que exigem capacidade intelectual, contribuindo assim para a criação de ativos tangíveis e intangíveis. Portanto para Sveiby (1998), o valor de mercado de uma empresa é composto por ativos tangíveis, ou seja, (capital financeiro) e também por ativos intangíveis (capital intelectual).

No contexto especifico das cooperativas, o desenvolvimento do conhecimento é um procedimento que necessita ser aperfeiçoado e isso deve ser feito mediante ações coletivas. Dessa forma, as necessidades dos cooperados são contempladas, não se restringindo a atender às características que regulam o setor (SILVA; BINOTTO, 2013). Além disso, os empreendimentos relacionados aos Agronegócios dependerão intensamente das habilidades de seus colaboradores para obterem sucesso, tanto para promoverem ações internas quanto para ações externas aos países de origem. As exportações estão relacionadas a maiores níveis de competitividade devido à oferta de produtos. Nesse contexto, o processo de inovação deve ser contínuo para atender ou criar demandas. Para isso deve haver investimentos em conhecimento organizacional para subsidiá-lo continuamente a inovação (SHELMAN; CONOLLY, 2012). 
$\mathrm{Na}$ revisão da literatura sobre capital intelectual há vastos estudos destacando a importância da identificação, evidenciação avaliação e gestão do capital intelectual dentre eles, destaca-se o de Kayo e Kimura (2008), que identificou a relação entre os ativos intangíveis (especificamente marcas e patentes) e o valor de mercado das empresas brasileiras de capital aberto. Os resultados demonstraram que a marca tem relação positiva e significativa com as variáveis de criação de valor analisadas (valor de mercado sobre valor contábil e o Q de Tobin). Scafarto, Ricci e Scafarto (2016) também realizaram um estudo com empresas internacionais de agronegócios, por meio de análises de correlação e regressão múltipla, o estudo testou o efeito positivo/negativo entre cada componente de IC e métricas de desempenho convencional.

Gracioli et al. (2012) em seu estudo em organizações que receberam o Prêmio Qualidade Rio Grande do Sul, no ano de 2004, analisaram a importância do capital intelectual como um elemento de inovação, verificando a contribuição dos componentes que o compõem na performance das empresas da amostra estudada. Já Benevene et al. (2017) em seu estudo analisou o entendimento do conceito de capital intelectual, por parte dos gestores entre organizações sem fins lucrativos, usando uma metodologia qualitativa com 81 entrevistas de gerentes seniores. Os autores verificaram a existência de uma lacuna considerável entre a percepção do conceito e o significado proposto pela literatura técnica, provocando assim discordâncias entre as aplicações práticas e questões de divulgação.

\section{PROCEDIMENTOS METODOLÓGICOS}

O presente estudo tem por objetivo verificar a presença dos elementos formadores do capital intelectual em uma cooperativa agropecuária, para tanto, foi realizado um estudo de caso com abordagem quantitativa em uma unidade localizada no estado do Mato Grosso do Sul.

Como técnica de coleta de dados foi utilizado o questionário adaptado do estudo realizado por Santos et al. (2016) para o contexto das cooperativas agropecuárias. Uma das vantagens na utilização de questionários é a facilidade de interpretação dos detalhes/características da amostra bem como a amplitude devido 
à grande variedade de questões sobre o tema específico estudado (CORDEIRO, 2013).

O questionário contém 62 questões, sendo 18 para identificar a presença de capital humano, 16 visando identificar a presença de capital relacional e 16 para identificar a presença de capital estrutural. As 12 questões finais investigam qual é a percepção dos dirigentes da cooperativa quanto à importância da identificação dos elementos formadores do capital intelectual. No questionário utiliza-se a escala de Likert de 5 pontos que é a mais comum em questionários, por representar respostas alternativas por meio de uma escala de percepção, como demonstrado a seguir: (1) discordo totalmente; (2) discordo parcialmente; (3) não discordo, nem concordo; (4) concordo parcialmente e (5) concordo totalmente.

A aplicação do questionário foi realizada no dia 19 de abril de 2017, de forma presencial com o gerente administrativo, na sede da cooperativa. A escolha do gerente administrativo se deu em função de sua visão sistêmica, vasta experiência profissional, bem como, pela sua participação no planejamento estratégico e tático da cooperativa agropecuária. A aplicação do questionário foi gravada para se extrair o máximo de informações referentes ao tema investigado.

Para identificar as medidas de tendência central de cada elemento formador do capital intelectual, foi realizada uma análise quantitativa utilizando a estatística descritiva por meio do software Stata versão 13.0. Á partir da medida de tendência central, foi realizada a classificação de cada elemento formador e da cooperativa como um todo, quanto ao nível de presença do capital intelectual com base no estudo de Gimenes et al. (2016). Os intervalos de valor e os níveis de presença de capital intelectual utilizados neste estudo são apresentados no Quadro 1.

Quadro 1 - Intervalos de valor e níveis de presença de capital intelectual

\begin{tabular}{|l|c|}
\hline \multicolumn{1}{|c|}{ Intervalo de valor } & Nível de presença de capital intelectual \\
\hline Inferior a 2,43 & Fraca \\
\hline Entre 2,44 e 3,92 & Média \\
\hline Superior a 3,92 & Forte \\
\hline
\end{tabular}

Fonte: Gimenes et al. (2016, p. 6). 


\section{APRESENTAÇÃO DOS RESULTADOS}

A evidenciação da presença dos elementos formadores do capital intelectual da cooperativa em estudo foi feita a partir da média das respostas obtidas do questionário aplicado. Apresentam-se, na sequência, as respostas obtidas para cada um dos elementos, reafirmando que o questionário utiliza a escala de Likert de 5 pontos.

\subsection{ELEMENTOS DO CAPITAL HUMANO}

A primeira parte do questionário é composta por 18 questões que averiguou a presença de capital humano na cooperativa, cujas respostas estão apresentadas no Quadro 2.

Quadro 2 - Identificação dos elementos do capital humano na cooperativa

\begin{tabular}{|l|l|c|}
\hline$N^{0}$ & \multicolumn{1}{|c|}{ Questão } & Resposta \\
\hline 1 & As competências dos funcionários, como um todo, estão no nível considerado ideal. & 4 \\
\hline 2 & $\begin{array}{l}\text { Quando um empregado deixa a empresa, esta tem um programa de treinamento e } \\
\text { formação para assegurar a sua substituição. }\end{array}$ & 4 \\
\hline 3 & $\begin{array}{l}\text { Normalmente no desenvolvimento das atividades, as tarefas são realizadas dentro } \\
\text { das datas limite estabelecidas. }\end{array}$ & 3 \\
\hline 4 & $\begin{array}{l}\text { A empresa consegue extrair o máximo rendimento dos funcionários quando estes } \\
\text { trabalham em equipe. }\end{array}$ & 5 \\
\hline 5 & $\begin{array}{l}\text { A empresa promove o desenvolvimento e a manutenção de relações internas entre } \\
\text { várias equipes de trabalho. }\end{array}$ & 5 \\
\hline 6 & A organização é bastante inovadora, originando, constantemente, novas ideias. \\
\hline 7 & $\begin{array}{l}\text { A empresa apoia o empregado na sua constante valorização profissional, sempre } \\
\text { que os mesmos os consideram necessários, realizando ações de formação } \\
\text { periódicas. }\end{array}$ & 5 \\
\hline 8 & Os funcionários da empresa são considerados inteligentes e criativos. & 5 \\
\hline 9 & Os funcionários são considerados os melhores dentro da empresa e do setor. & 4 \\
\hline 10 & Os funcionários estão satisfeitos com a empresa. & 5 \\
\hline 11 & $\begin{array}{l}\text { Os funcionários desempenham as suas tarefas ao máximo das suas capacidades, de } \\
\text { forma completamente satisfatória. }\end{array}$ & 4 \\
\hline 12 & $\begin{array}{l}\text { O nosso processo de recrutamento é muito seletivo. Estamos direcionados para } \\
\text { contratar os melhores candidatos disponíveis. }\end{array}$ & 3 \\
\hline 13 & $\begin{array}{l}\text { Se determinados funcionários, subitamente, deixassem a empresa, estaríamos em } \\
\text { grandes problemas. }\end{array}$ & 1 \\
\hline 14 & Os funcionários geralmente desempenham as suas tarefas sem grande empenho. \\
\hline 15 & $\begin{array}{l}\text { Os funcionários vão aprendendo uns com os outros, existindo um elevado nível de } \\
\text { troca de informação e conhecimento entre eles. }\end{array}$ & 1 \\
\hline 16 & $\begin{array}{l}\text { Os funcionários estão empenhados a levarem as suas ideias a reuniões e a grupos } \\
\text { de discussão. }\end{array}$ & 4 \\
\hline 17 & $\begin{array}{l}\text { O fato de os funcionários desempenharem as suas tarefas no máximo das suas } \\
\text { capacidades, diferencia a nossa empresa das outras empresas do setor. }\end{array}$ \\
\hline
\end{tabular}

Ágora: R. Divulg. Cient., v. 22, n. 2, p. 24-44, jul./dez. 2017 (ISSNe 2237-9010) 
18 Com a saída de um empregado da equipe de trabalho, poder-se-á perder algum valor no capital humano da empresa.

Fonte: Elaborado pelos autores.

\subsection{ELEMENTOS DO CAPITAL RELACIONAL}

Na segunda parte do questionário buscou-se identificar a presença de capital relacional na cooperativa. Para tanto, elaboraram-se também 18 questões, cujas respostas são apresentadas no Quadro 3.

Quadro 3 - Identificação dos elementos do capital relacional na cooperativa

\begin{tabular}{|l|l|c|}
\hline $\mathbf{N}^{\circ}$ & \multicolumn{1}{|c|}{ Questão } & Resposta \\
\hline 19 & $\begin{array}{l}\text { Uma pesquisa com os clientes indicaria que eles, genericamente, estão satisfeitos } \\
\text { com a nossa organização. }\end{array}$ & 5 \\
\hline 20 & $\begin{array}{l}\text { A empresa tem conseguido reduzir significativamente o tempo de resolução das } \\
\text { reclamações/problemas dos clientes. }\end{array}$ & 5 \\
\hline 21 & $\begin{array}{l}\text { A nossa participação de mercado tem aumentado significativamente nos últimos } \\
\text { anos.A nossa quota de mercado é das mais altas do setor. }\end{array}$ & 5 \\
\hline 22 & $\begin{array}{l}\text { A longevidade de relacionamento que mantemos com os nossos clientes é } \\
\text { admirada/invejada pelos nossos concorrentes. }\end{array}$ & 3 \\
\hline 23 & $\begin{array}{l}\text { A organização tem conseguido fornecer maior nível de valor acrescentado por } \\
\text { produto/serviço, comparativamente com as empresas do setor. }\end{array}$ & 4 \\
\hline 24 & Os nossos clientes são leais, mais do que a qualquer outra empresa do setor. \\
\hline 25 & $\begin{array}{l}\text { No que respeita a novos negócios a empresa tem sido escolhida pelos clientes, em } \\
\text { detrimento dos nossos concorrentes diretos. }\end{array}$ & 4 \\
\hline 26 & A nossa organização orgulha-se de ser totalmente orientada para o mercado. \\
\hline 27 & $\begin{array}{l}\text { Reunimo-nos periodicamente com os clientes para investigar o que eles esperam de } \\
\text { nós. A informação recolhida do feedback dos clientes é simultaneamente disseminada } \\
\text { pela empresa. }\end{array}$ & 2 \\
\hline 28 & $\begin{array}{l}\text { A maior parte dos funcionários compreende os nossos mercados alvo e perfil dos } \\
\text { nossos clientes. }\end{array}$ & 5 \\
\hline 29 & $\begin{array}{l}\text { Geralmente não nos preocupamos com o que os nossos clientes pensam ou esperam } \\
\text { de nós. }\end{array}$ & 1 \\
\hline 30 & $\begin{array}{l}\text { Investimos nos nossos clientes através da procura contínua de satisfação das suas } \\
\text { necessidades. }\end{array}$ & 5 \\
\hline 31 & $\begin{array}{l}\text { Estamos confiantes, de que, no futuro, os clientes irão manter o seu relacionamento } \\
\text { comercial conosco. }\end{array}$ & 5 \\
\hline 32 & $\begin{array}{l}\text { Dentro das nossas possibilidades, conseguimos extrair o máximo de feedback dos } \\
\text { nossos clientes. }\end{array}$ & 5 \\
\hline 33 & A "marca" da empresa é bastante reconhecida e respeitada pelo mercado. \\
\hline 34 & $\begin{array}{l}\text { A relação com os fornecedores e parceiros comerciais é de confiança e de } \\
\text { comprometimento. }\end{array}$ \\
\hline Fon & 5 \\
\hline
\end{tabular}

Fonte: Elaborado pelos autores.

Ágora: R. Divulg. Cient., v. 22, n. 2, p. 24-44, jul./dez. 2017 (ISSNe 2237-9010) 


\subsection{ELEMENTOS DO CAPITAL ESTRUTURAL}

O objetivo dessa seção do questionário visou investigar a presença de capital estrutural na cooperativa. Esta etapa contem 16 questões, cujas respostas são apresentadas no Quadro 4.

Quadro 4 - Identificação dos elementos do capital estrutural da cooperativa

\begin{tabular}{|c|c|c|}
\hline $\mathbf{N}^{0}$ & Questão & Resposta \\
\hline 35 & $\begin{array}{l}\text { A empresa apresenta o "custo de transação" mais baixo dentro do seu setor de } \\
\text { atividade. Note que "transação" é definida como uma operação de troca completa } \\
\text { no negócio. }\end{array}$ & 2 \\
\hline 36 & Temos conseguido melhorar continuamente a relação proveito/custo. & 5 \\
\hline 37 & A margem de lucro por funcionário tem crescido nos últimos anos. & 5 \\
\hline 38 & A margem de lucro por funcionário é uma das melhores do setor. & 3 \\
\hline 39 & $\begin{array}{l}\text { O tempo de realização de uma operação completa (processo produtivo) tem } \\
\text { diminuído ao longo dos últimos anos. }\end{array}$ & 5 \\
\hline 40 & $\begin{array}{l}\text { O tempo utilizado na realização de uma operação completa é um dos melhores do } \\
\text { setor. }\end{array}$ & 5 \\
\hline 41 & Grande parte das boas novas ideias geradas na empresa são implementadas. & 5 \\
\hline 42 & $\begin{array}{l}\text { A nossa empresa aposta no desenvolvimento de novas ideias, produtos e } \\
\text { processos. }\end{array}$ & 5 \\
\hline 43 & $\begin{array}{l}\text { A empresa desenvolve mais novas ideias, produtos e processos do que qualquer } \\
\text { outra empresa no setor. }\end{array}$ & 3 \\
\hline 44 & A empresa orgulha-se da sua eficiência nos últimos anos. & 5 \\
\hline 45 & O nosso sistema de informação torna fácil o acesso à informação relevante. & 3 \\
\hline 46 & Os sistemas e processos dentro da organização apoiam e promovem a inovação. & 5 \\
\hline 47 & A organização é extremamente burocrática. & 2 \\
\hline 48 & $\begin{array}{l}\text { A estrutura organizacional impede os funcionários de estarem muito isolados uns } \\
\text { dos outros. }\end{array}$ & 1 \\
\hline 49 & A cultura organizacional é confortável e compreensiva. & 5 \\
\hline 50 & Na organização não existe partilha de conhecimento. & 5 \\
\hline
\end{tabular}

Fonte: Elaborado pelos autores.

\subsection{IMPORTÂNCIA DA IDENTIFICAÇÃO DO CAPITAL INTELECTUAL}

$\mathrm{Na}$ quarta e última etapa do questionário, foram elaboradas 12 questões relativas à importância da percepção do gestor quanto à identificação do capital intelectual. As respostas estão apresentadas no Quadro 5. 
Quadro 5 - Percepção do gestor sobre o capital intelectual na cooperativa

\begin{tabular}{|c|l|c|}
\hline $\mathbf{N}^{\circ}$ & \multicolumn{1}{|c|}{ Questão } & Resposta \\
\hline 51 & $\begin{array}{l}\text { Na definição do modelo empresarial, damos muita importância aos elementos do } \\
\text { capital intelectual. }\end{array}$ & 5 \\
\hline 52 & $\begin{array}{l}\text { A empresa procura realizar tentativas sistemáticas de valorização (mensuração) e } \\
\text { reporte (divulgação) ao ambiente externo sobre o capital intelectual. }\end{array}$ & 5 \\
\hline 53 & Existe informação sobre capital intelectual por parte da organização. & 5 \\
\hline 54 & $\begin{array}{l}\text { Relativamente à empresa, o mercado reconhece um valor superior ao valor contábil } \\
\text { registrado. }\end{array}$ & 5 \\
\hline 55 & A empresa possui medidas de avaliação de desempenho não financeiras. \\
\hline 56 & $\begin{array}{l}\text { O mercado cada vez mais utiliza e necessita de medidas não financeiras para as } \\
\text { suas análises e tomadas de decisão. }\end{array}$ & 5 \\
\hline 57 & $\begin{array}{l}\text { Os investidores poderão beneficiar grandemente do conhecimento sobre a evolução } \\
\text { dos recursos humanos de uma determinada organização. }\end{array}$ & 5 \\
\hline 58 & $\begin{array}{l}\text { Atualmente um dos principais fatores de êxito das empresas é a capacidade de } \\
\text { aproveitar as novas oportunidades de negócio, a qual requer um conjunto de } \\
\text { intangíveis que está inerente ao talento das pessoas. }\end{array}$ & 5 \\
\hline 59 & $\begin{array}{l}\text { Considero necessário um conjunto de normas para o reconhecimento de bens } \\
\text { intelectuais da empresa. }\end{array}$ & 1 \\
\hline 60 & $\begin{array}{l}\text { A capacidade informativa das demonstrações financeiras sobre a posição financeira } \\
\text { atual e futura das organizações tem diminuído significativamente nos últimos anos. }\end{array}$ & 1 \\
\hline 61 & $\begin{array}{l}\text { É vantajoso para as empresas gerar informação relativa ao capital intelectual numa } \\
\text { perspectiva custo/benefício. }\end{array}$ & 5 \\
\hline 62 & $\begin{array}{l}\text { A importância relativa dos elementos geradores de valor (trabalho, terra, capital e } \\
\text { conhecimento) tem vindo a alterar, tendo o conhecimento ganhou importância em } \\
\text { detrimento dos restantes elementos. }\end{array}$ & 5 \\
\hline
\end{tabular}

Fonte: Elaborado pelos autores.

\subsection{DISCUSSÃO DOS RESULTADOS}

A verificação da presença dos elementos formadores do capital intelectual da cooperativa em estudo foi realizada a partir das medidas de tendência central (média) das respostas obtidas no questionário referente a cada elemento que compõem o capital intelectual. As medidas de tendência central obtidas são apresentadas na Tabela 1.

Tabela 1 - Média dos elementos do capital intelectual

\begin{tabular}{ll}
\multicolumn{1}{c}{ Elementos } & Média \\
\hline Capital humano & 4,062 \\
Capital relacional & 4,063 \\
Capital estrutural & 4,000 \\
Outras questões & 4,250 \\
\hline
\end{tabular}

Fonte: Elaborado pelos autores.

A partir da apresentação da média, discute-se num primeiro momento a evidenciação dos níveis de presença dos elementos do capital intelectual (capital

Ágora: R. Divulg. Cient., v. 22, n. 2, p. 24-44, jul./dez. 2017 (ISSNe 2237-9010) 
humano, relacional e estrutural) e em um segundo momento discute-se os resultados da percepção do gestor sobre o capital intelectual na cooperativa.

O valor médio do nível de presença de capital humano foi igual a 4,062. Considerando os intervalos de valor e níveis de presença de capital intelectual propostos por Gimenes, et al. (2016), verifica-se que a média obtida demonstra uma forte presença do elemento capital humano na cooperativa. Pode-se considerar que o todas as características relacionadas ao Capital Humano (boa relação entre os funcionários, a capacidade de trabalhar em equipe, criatividade, proatividade) são considerados de extrema importância para o setor agropecuário, uma vez que permite desse modo avaliar e identificar antecipadamente as necessidades de inovações e desenvolvimento de produtos ou serviços contribuindo assim significativamente para o acerto ou o erro no mercado (SHELMAN; CONOLLY, 2012).

Assim como o capital humano, o capital relacional também apresentou um nível de presença forte, pois o valor médio desse elemento totalizou 4,063 permitindo considerar uma forte participação deste elemento na construção do capital intelectual da organização. Alguns fatores podem justificar esse nível significativo de capital relacional, dentre eles destaca-se a capacidade dos gestores em obter e utilizar as informações sobre o perfil e comportamento dos clientes e também à fidelidade conquistada ao longo dos anos entre a cooperativa, seus cooperados e seus clientes. Observa-se que os resultados aqui apresentados corroboram com os resultados de Nagano, Matheus e Merlo (2005), pois assim como nas usinas, a cooperativa também investe na melhoria da qualidade de seus relacionamentos com seus cooperados, clientes, fornecedores, parceiros e também com seus colaboradores.

Com relação ao capital estrutural, o valor médio apurado foi de 4,00 demonstrando também uma forte presença desse elemento no ativo intangível da cooperativa. É importante considerar as relações que a literatura estabelece entre os elementos que identificam a presença do capital intelectual nas organizações, dentre elas como sendo positiva a relação entre o capital humano e o capital estrutural. Pode-se perceber que na cooperativa, a forte participação do capital humano colaborou para a forte participação do capital estrutural na evidenciação do capital intelectual. Este resultado se deu em razão do capital humano criar o principal elo 
para a interação social, uma vez que é o capital humano que constrói e sustenta o capital estrutural (NAHAPIET; GHOSHAL, 1998).

No que se refere à importância atribuída ao capital intelectual pelo gestor da cooperativa evidenciou-se uma média de 4,25, representando que o gestor considera o capital intelectual importante e a sua evidenciação relevante para a tomada de decisão. Este resultado corrobora o estudo de Antunes (2005) que identificou que os gerentes valorizam e investem nos elementos do capital intelectual, assim como, com o estudo de Arruda (2009) que observou uma preocupação dos gestores em divulgar para o mercado informações sobre o capital intelectual, de modo a oferecer vantagens para as companhias e para os investidores que tomarão decisões mais acertadas no futuro. Na maioria das vezes, o capital intelectual não é quantificado nas organizações, impossibilitando uma identificação mais consistente e robusta de seus elementos (ANTUNES; MARTINS, 2007a).

\section{CONCLUSÕES}

Dada a importância do capital intelectual para o sucesso organizacional e do escasso número de estudos que abordam essa temática no contexto do agronegócio, este estudo teve por objetivo verificar a presença dos elementos formadores do capital intelectual em uma cooperativa agropecuária visando contribuir para o preenchimento dessa lacuna na produção científica nacional.

Como principal contribuição, este estudo apresenta evidências de forte presença de todos os elementos formadores do capital intelectual, sendo eles o capital humano $(4,062)$, capital relacional $(4,063)$ e o capital estrutural $(4,000)$. Quanto à importância da identificação do capital intelectual por parte do gestor, verificou-se que o capital intelectual é importante e a sua evidenciação é relevante para a tomada de decisão.

O capital humano apresentou como um elemento significativo na composição do capital intelectual da cooperativa, sendo que o bom relacionamento entre os funcionários, a criatividade, o know-how e a capacidade de trabalhar em equipe contribuíram substancialmente para a construção desse valor. Cabe ressaltar a importância do capital estrutural que envolve uma gama de instrumentos de apoio no compartilhamento e na manutenção da expertise, do aprendizado, do conhecimento 
e da memória organizacional. A forte presença do capital relacional, também significativa, pode ser justificada pela capacidade estratégica dos gestores e também à fidelidade conquistada ao longo dos anos entre a cooperativa e sua rede de relacionamentos. Partindo dessas informações, as decisões estratégicas sobre investimentos nesses ativos podem ser feita de forma efetiva, proporcionando vantagem competitiva em um mercado cada vez mais dinâmico e concorrido.

Como limitações deste estudo, têm-se a aplicação do questionário a apena um gestor, haja vista que, dado o perfil da cooperativa, era o único que apresentou condições de responder ao questionário por ter uma visão abrangente de todas as áreas da organização. Outra limitação refere-se a impossibilidade de análise comparativa com outros estudos, pois verifica-se uma reduzida quantidade de estudos existentes que analisam, avaliam e identificam a temática $\mathrm{Cl}$ no contexto do agronegócio.

Sugere-se que novos estudos sejam desenvolvidos com um número maior de cooperativas agropecuárias e se possível com um maior número de respondentes visando obter resultados que possibilitem a comparação e desenvolvimento da área em estudo. Sugere-se também que sejam realizadas análises quantitativas mais robustas visando identificar a existência de associação da presença dos elementos do capital intelectual com as características socioeconômicas das cooperativas agropecuárias.

\section{REFERÊNCIAS}

ANTUNES, M. T. Capital Intelectual. São Paulo: Atlas, 2000.

A Controladoria e o Capital Intelectual: um estudo empírico sobre suagestão.

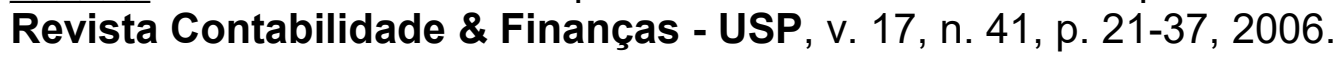

O Capital Intelectual segundo o entendimento de gestores de empresas brasileiras. Revista Brasileira de Gestão de Negócios, v. 7, n. 19, p. 9-20, 2005.

ANTUNES, M. T.; MARTINS, E. Capital intelectual: seu entendimento e seus impactos no desempenho de grandes empresas brasileiras. BASE - Revista de Administração e Contabilidade da UNISINOS, v. 4, n. 1, p. 5-21, 2007a.

. Gerenciando o Capital Intelectual: uma proposta baseada na controladoria de grandes empresas brasileiras. REAd. Revista Eletrônica de Administração, v. 13 , n. 1, p. 1-23, $2007 b$. 
ARRUDA, B. B. H. Evidenciação de elementos do capital intelectual nos relatórios da administração de companhias brasileiras pertencentes ao nível 2 de governança corporativa. Enfoque Reflexão Contábil, v. 28, n. 3, p. 69-80, 2009.

BARBOSA, J. G. P; GOMES, J. S. Um estudo exploratório do controle gerencial de ativos e recursos intangíveis em empresas brasileiras. Revista Administração Contemporânea, v.6, n.2, p.29-48, 2002.

BARROS, F. S. O.; PONTE, V. M. R.; FARIAS, I. Q. Gerenciamento do capital intelectual: um estudo em empresas do setor têxtil cearense. BASE - Revista de Administração e Contabilidade da UNISINOS, v. 4, n. 2, p. 137-148, 2007.

BENEVENE, P. et al. Representation of intellectual capital's components amongst Italian social enterprises, Journal of Intellectual Capital, v. 18, n. 3, p. 564-587, 2017.

BROOKING, Annie. Intellectual Capital: Core Asset for the Third Millennium Enterprise. Boston: Thomson Publishing Inc., 1996.

El capital intelectual: el principal activo de las empresas del tercer milenio. Barcelona: Ed. Paidós Ibérica, S.A, 1997.

CARLOS FILHO, F. A.et al. Importância e contribuição do ativo intangível: percepção dos empreendedores de micro e pequenas empresas sobre o capital intelectual. Revista Organizações em Contexto, v. 10, n. 20, p. 1-27, 2014.

COELHO, I. G.; FERREIRA, M. A. M. Um estudo empírico sobre o Planejamento Estratégico em cooperativas agropecuárias lácteas. Revista de Economia e Administração, v. 9, n. 4, p. 493-522, 2010.

COLAUTO, R. D. et al. Avaliação do capital intelectual desenvolvido em organizações não governamentais: comparação entre entidades brasileiras e portuguesas. Enfoque Reflexão Contábil, v. 30, n. 2, p. 9-23, 2011.

COOK, M.; ILIOPOULOS, C. Solutions to property rights constraints in producerowned and controlled organizations: prerequisite for agrichain leadership? In: international conference on chain management in agribusiness and food industry, 3 ., 1998, Wageningen. Proceedings... Wageningen: Wageningen Agricultural University, p. 541-553, 1998.

CORDEIRO, A. S. G. Capital intelectual e desempenho organizacional no sector farmacêutico português. 86 f. Dissertação (Mestrado em Gestão de Recursos Humanos e Comportamento Organizacional) - Instituto Superior Miguel Torga, Coimbra, Portugal, 2013.

CRUZ, J. C. S.; ALVES, M. T. V. D. Capital intelectual: práticas de divulgação de informação em empresas portuguesas. Revista Universo Contábil, v. 9, n. 2, p. 174-194, 2013. 
DENACOOP - DEPARTAMENTO DE COOPERATIVISMO E ASSOCIATIVISMO RURAL. Plano de modernização do cooperativismo brasileiro. MAA/SDR/DENACOOP. Brasília, DF, 1996.

DORCE, L. C.; CAVALHEIRO, R. T.; GIMENES, R. M. T. Capital Intelectual: Uma Análise Bibliométrica da Produção Científica Brasileira. Revista FSA, v. 14, n. 3, p. 28-54, 2017.

EDVINSSON, L.; MALONE, M. Capital intelectual: descobrindo o valor real de sua empresa pela identificação de seus valores internos. São Paulo: Makron Books, 1998.

ENSSLIN, S. R.et al. Uma Metodologia Multicritério (MCDA-C) para apoiar o gerenciamento do capital intelectual organizacional. RAM -Revista de Administração Mackenzie, v. 9, n. 7, p. 136-163, 2008.

FERREIRA, M. A. M. Eficiência das cooperativas na indústria de laticínios. 155 p. Tese (Doutorado em Economia Aplicada) - Departamento de Economia Rural, Universidade Federal de Viçosa, 2005.

GIMENES, R. M. T. et al. Capital Intelectual em Organizações Hospitalares. In. Congresso Brasileiro de Contabilidade, $2^{\circ}$, 2016, Fortaleza. Anais... Fortaleza: CBC. 2016.

GRACIOLI, C.et al. Capital intelectual: uma ferramenta inovadora na busca por vantagens competitivas. Revista de Administração e Inovação, v. 9, n. 4, p. 96120, 2012.

JOIA, L. A. Medindo o capital intelectual. Revista de Administração de Empresas, v. 41 , n. 2, p. 54-63, 2001.

. Governo eletrônico e capital intelectual nas organizações públicas. Revista de Administração Pública, v. 43, n. 6, p. 1379-1405, 2009.

MELLO, F. J.; RICCI, R. Cooperativas de Leite de MG: Um panorama da situação atual frente à internacionalização dos mercados. Belo Horizonte: PUC - MG, 1996. 95 p. Trabalho não publicado.

NAGANO, M. S.; MATHEUS, L. F.; MERLO, E. M. Análise da identificação e da gestão do capital intelectual nas usinas sucroalcooleiras. REAd. Revista Eletrônica de Administração, v. 11, n. 4, p. 1-25, 2005.

NAHAPIET, J.; GHOSHAL, S. Social capital, intellectual capital and the organizational advantage. Academy of Management Review, v. 23, n. 2, p. $242-$ 246, 1998.

OLIVEIRA, J. M.; BEUREN, I. M. O tratamento contábil do capital intelectual em empresas com valor de mercado superior ao valor contábil. Revista Contabilidade \&Finanças - USP, v. 14, n. 32, p. 81-98, 2003. 
OCB - ORGANIZAÇÃO DAS COOPERATIVAS BRASILEIRAS. História do Cooperativismo. Disponível em:<http://www.somoscooperativismo.coop.br/historiado-cooperativismo>. Acesso em: 14 mar. 2017.

PORTER, M. E. Estratégia competitiva: técnicas para a análise de indústrias e da concorrência. Tradução de Elizabeth Maria de Pinho Braga; revisão técnica Jorge A. GarciaGomes. 7.ed. Rio de Janeiro: Campus, 1991.

REINA, D. et al. Evidenciação do capital intelectual em empresas do setor de tecnologia da informação e do setor de telecomunicações listadas na BM\&FBovespa nos anos de 2007 a 2009. Enfoque Reflexão Contábil, v. 30, n. 1, p. 63-82, 2011.

REIS, L. G. D. As dificuldades de mensuração e consequente divulgação nas demonstrações contábeis do capital intelectual: uma reflexão teórica. Contabilidade Vista \& Revista, v. 16, n. 2, p. 43-60, 2005.

SANTOS, T. G. S. et al. Capital intelectual em organizações hospitalares: um estudo de caso do Hospital Santa Casa de Maringá. Revista Espacios, v. 37, n. 36, p. 115, 2016.

SEBRAE- SERVIÇO BRASILEIRO DE APOIO ÀS MICRO E PEQUENAS

EMPRESAS. Cooperativa: série empreendimentos coletivos. Brasília: SEBRAE/DF, 2009.

SCAFARTO, V.; RICCI, F.; SCAFARTO, F. Intellectual capital and firm performance in the global agribusiness industry. The moderating role of human capital. Journal of Intellectual Capital, v. 17 n. 3, p. 530-552, 2016.

SILVA, I. F.; BINOTTO, E. O conhecimento e a aprendizagem organizacional no contexto de uma organização rural. Perspectivas em Gestão \& Conhecimento, João Pessoa, v. 3, n. 1, 2013.

SILVA, C. D. F.; NAGANO, M. S.;MERLO, E. M. Gestão do capital de relacionamento: estudo de caso em uma tradicional fábrica no Brasil. RAM - Revista de Administração Mackenzie, v.9, n.6, p.53-76, 2008.

SHELMAN, M.; CONNOLLY, A. J. The human capital issue: ensuring the future of food and agribusiness. International Food and Agribusiness Management Review, v. 15, 2012.

SOARES, M. M.; SOBRINHO, A. D. M. Microfinanças: O papel do Banco Central do Brasil e a importância do cooperativismo de crédito. 2.ed. Brasília: BCB, 2008.

SOUSA, B. J.et al. Um estudo sobre a evidenciação de capital intelectual nos relatórios da administração das 15 maiores distribuidoras de energia elétrica do Brasil nos anos de 2006 e 2007. Contabilidade, Gestão e Governança, v. 11, n. 12, p. 187-207, 2008.

STEWART, T. A. Capital intelectual: a nova vantagem competitiva das empresas. 4. ed. Rio de Janeiro: Campus, 1998. 
SVEIBY, K. A nova riqueza das organizações. Rio de Janeiro: Campus, 1998.

TEH, C. C.; KAYO, E. K.; KIMURA, H. Marcas, patentes e criação de valor. RAM Revista de Administração Mackenzie, v.9, n.1, p.86-106, 2008.

VARGAS, V. C. C.et al. Avaliação dos intangíveis: uma aplicação em capital humano. Gestão \& Produção, v.15, n.3, p.619-634, 2008.

ZYLBERSZTAJN, D. Quatro estratégias fundamentais para as cooperativas agrícolas. In: BRAGA, M. J.; REIS, B. S. (orgs.). Agronegócio cooperativo: reestruturação e estratégias. Viçosa: UFV, 2002. p. 55-75.

Artigo recebido em: 29/08/2017

Artigo aprovado em: 24/11/2017

Artigo publicado em: 19/12/2017 